\title{
HUBUNGAN KECEMASAN DENGAN KUALITAS TIDUR PADA PASIEN PRE OPERASI TRANSURETHRAL RESECTION OF THE PROSTATE (TURP) DI RUMAH SAKIT UMUM IMELDA PEKERJA INDONESIA MEDAN
}

\author{
Christine Handayani Siburian \\ Program Studi S1 Keperawatan, Universitas Imelda Medan \\ E-mail: christinehandayani4@gmail.com
}

\begin{abstract}
Benign Prostatic Hyperplasia (BPH) is an enlargement of the prostate gland that generally occurs in older men and if left untreated can lead to complications. BPH can be treated with a medical procedure, namely the Transurethral Resection of the Prostate (TURP) surgical procedure. Before the action, the patient will experience anxiety. Anxiety arises because of excessive fear that can affect the quality of sleep. The purpose of this study was to determine the relationship between anxiety and sleep quality in patients with preoperative Transurethral Resection of the Prostate (TURP). The research design used was cross sectional. The sample is 31 respondents of preoperative patients at Rumah Sakit Umum Imelda Pekerja Indonesia Medan with the sampling technique used is accidental sampling. The research data was collected using the Hamilton Scale for Anxiety (HRS-A) questionnaire and The Pittsburgh Sleep Quality Index (PSQI) questionnaire. Data were analyzed by Spearman Rho correlation test. The results showed that there was a relationship between anxiety and sleep quality in patients with preoperative Transurethral Resection of the Prostate (TURP) $(\mathrm{p}=0.000, \mathrm{r}=0.907)$. The results of this study can recommend that the need for nursing actions that can reduce anxiety so that the patient's sleep quality can be better.
\end{abstract}

Keyword: TURP, Anxiety, Sleep Quality

\begin{abstract}
Abstrak
Benign Prostatic Hyperplasia (BPH) adalah pembesaran kelenjar prostat yang pada umumnya terjadi pada pria yang lebih tua dan apabila tidak diobati dapat menyebabkan komplikasi. BPH dapat ditangani dengan tindakan medis yaitu prosedur pembedahan Transurethral Resection of the Prostate (TURP). Sebelum dilakukan tindakan tersebut, pasien akan mengalami kecemasan. Kecemasan timbul karena rasa takut berlebih yang dapat mempengaruhi kualitas tidur. Tujuan penelitian ini adalah mengetahui hubungan kecemasan dengan kualitas tidur pada pasien pre operasi Transurethral Resection of the Prostate (TURP). Desain penelitian yang digunakan Cross Sectional. Sampel adalah 31 responden pasien pre operasi di Rumah Sakit Umum Imelda Pekerja Indonesia Medan dengan teknik pengambilan sampel adalah teknik accidental sampling. Pengumpulan data penelitian menggunakan kuesioner Hamilton Scale for Anxiety (HRS-A) dan kuesioner The Pittsburgh Sleep Quality Index (PSQI). Data dianalisis dengan uji korelasi Spearman Rho. Hasil didapatkan ada hubungan kecemasan dengan kualitas tidur pada pasien pre operasi Transurethral Resection of the Prostate (TURP) $(\mathrm{p}=0,000, \mathrm{r}=0,907)$. Hasil penelitian ini dapat merekomendasikan bahwa perlunya tindakan keperawatan yang dapat mengurangi kecemasan agar kualitas tidur pasien dapat menjadi lebih baik.
\end{abstract}

Kata kunci: TURP, Kecemasan, Kualitas Tidur 


\section{PENDAHULUAN}

Benign Prostatic Hyperplasia (BPH) adalah pembesaran kelenjar prostat yang pada umumnya terjadi pada pria yang lebih tua dan apabila tidak diobati dapat menyebabkan komplikasi. Kelenjar prostat merupakan reproduksi pria yang penting dimana terletak di bawah kandung kemih sehingga apabila kelenjar prostat membesar dapat menyebabkan masalah kencing, seperti sering buang air kecil atau ketidakmampuan dalam mengosongkan kandung kemih [1]. Kasus BPH terus meningkat, banyaknya jumlah kasus BPH di RSUD Arifin Achmad Provinsi Riau yaitumencapai 456 kasus pada tahun 2011-2014. Hasil penelitian Tabanan menunjukkan bahwa tahun 2018 jumlah kasus BPH sebanyak 112 kasus dan pada tahun 2019 meningkat dengan jumlah sebanyak 144 kasus [2].

Kasus BPH dapat ditangani dengan tindakan medis yaitu prosedur pembedahan yang salah satunya adalah Transurethral Resection of the Prostate (TURP). TURP merupakan tindakan pembedahan pada pasien Benign Prostatic Hyperplasia (BPH) untuk menyingkirkan jaringan prostat penyebab obstruksi saluran kemih [3]. Pasien yang akan menjalani operasi pembedahan akan mengalami kecemasan. Kecemasan adalah gangguan alam perasaan yang ditandai dengan perasaan takut dan khawatir yang mendalam dan berkelanjutan, tidak mengalami gangguan dalam menilai realistis, kepribadian tetap utuh, perilaku dapat terganggu tetapi masih dalam batas-batas normal [4]. Kecemasan dapat terjadi pada pasien yang akan menjalani operasi dengan alasan bahwa pasien takut akan nyeri setelah pembedahan, takut terjadi perubahan fisik dan takut operasi gagal [5].

Kecemasan pada pasien yang akan menjadi operasi TURP belum ada yang meneliti. Untuk itu, peneliti melakukan studi pendahuluan di Rumah Sakit Umum Imelda Pekerja Indonesia Medan untuk mengetahui kecemasan yang dirasakan pasien yang akan menjalani operasi TURP. Hasil wawancara pada 10 pasien menunjukkan bahwa seluruhnya pasien mengalami kecemasan dengan alasan sangat takut dimasukkan alat ke alat perkemihan, sangat takut tindakan medis gagal, takut merasa nyeri, dan takut menimbulkan alat kelamin tidak berfungsi secara normal. Secara objektif kecemasan pasien timbul seperti jantung berdetak lebih kencang, keringat dingin, sulit fokus ketika berbicara, mudah tersinggung, dan kepala sering pusing. Selain itu, kecemasan yang juga sering timbul pada pasien pre operasi dapat mempengaruhi kualitas tidur.

Tidur adalah proses dimana mata tertutup selama beberapa periode yang memberikan istirahat total bagi mental dan aktivitas fisik manusia, kecuali fungsi beberapa organ vital seperti jantung, paruparu, hati, sirkulasi darah dan organ dalam lainnya. Studi penelitian melaporkan bahwa rasa takut dan cemas terhadap kemungkinan terjadinya disabilitas sangat mempengaruhi kualitas tidur pada pasien pre operative. Hasil studi pendahuluan yang dilakukan pada 10 orang pasien pre operasi TURP menunjukkan sulit tidur karena pasien merasakan nyeri pada daerah perkemihan, adanya rasa takut yang berlebih ketika akan dilakukannya operasi, banyak berfikir tentang sesuatu hal yang akan terjadi setelah operasi, dan berfikir apayang harus dilakukan apabila operasi gagal. Kualitas tidur buruk terjadi karena adanya kecemasan yang berlebihan dimana kecemasan yang timbul karena adanya rasa takut untuk menjalani operasi [6]. Oleh karena itu, berdasarkan latar belakang di atas, maka peneliti tertarik untuk meneliti "hubungan kecemasan dengan kualitas tidur pada pasien pre operasi Transurethral Resection of the Prostate (TURP) di Rumah Sakit Umum Imelda Pekerja Indonesia Medan".

\section{METODE PENELITIAN}

Desain penelitian ini adalah kuantitatif bersifat deskriptif korelatif atau disebut dengan cross sectional. Penelitian ini dilakukan di Ruangan Rawat Inap Anggrek Rumah Sakit Umum Imelda Pekerja Indonesia Medan pada bulan Maret sampai dengan bulan Agustus 2021. Populasi dalam penelitian ini adalah seluruh pasien yang 
akan menjalani operaasi Transurethral Resection of the Prostate (TURP). Jumlah sampel pada penelitian ini berdasarkan Rumus Slovin yaitu 31 orang. Instrumen yang digunakan yaitu Hamilton Scale for Anxiety (HRS-A) dan kuesioner The Pittsburgh Sleep Quality Index (PSQI). Analisa data yang digunakan adalah analisa uji Spearmen Rho.

\section{HASIL PENELITIAN \\ Analisa Univariat \\ Tabel 1. Karakteristik Responden Pasien Pre Operasi Transurethral Resection of the Prostate (TURP) di Rumah Sakit Umum Imelda Pekerja Indonesia Medan}

\begin{tabular}{|c|c|c|}
\hline \multirow{2}{*}{ Karakteristik } & \multicolumn{2}{|c|}{ Responden } \\
\hline & $\mathbf{F}$ & $\%$ \\
\hline \multicolumn{3}{|l|}{ Umur } \\
\hline $\begin{array}{l}\text { Lansia Akhir } \\
\text { (56-65Tahun ) }\end{array}$ & 24 & 77,4 \\
\hline Manula (> 65 Tahun) & 7 & 22,6 \\
\hline Total & 31 & 100,0 \\
\hline \multicolumn{3}{|l|}{ Status Pernikahan } \\
\hline Menikah & 26 & 83,9 \\
\hline Duda & 5 & 16,1 \\
\hline Total & 31 & 100,0 \\
\hline \multicolumn{3}{|l|}{ Pendidikan Terakhir } \\
\hline SD & 8 & 25,8 \\
\hline SMP & 5 & 16,1 \\
\hline SMA & 6 & 19,4 \\
\hline D3 & 6 & 19,4 \\
\hline S1 & 6 & 19,5 \\
\hline Total & 31 & 100,0 \\
\hline \multicolumn{3}{|l|}{ Pekerjaan } \\
\hline Tidak Bekerja/ IRT & 2 & 6,5 \\
\hline Petani & 10 & 32,3 \\
\hline Buruh & 2 & 4,0 \\
\hline Karyawan Swasta & 2 & 6,5 \\
\hline PNS/BUMN & 10 & 32,3 \\
\hline Wiraswasta & 5 & 16,1 \\
\hline Total & 31 & 100,0 \\
\hline \multicolumn{3}{|l|}{ Operasi Keberapa } \\
\hline 1 & 16 & 51,6 \\
\hline 2 & 11 & 35,5 \\
\hline 3 & 4 & 12,9 \\
\hline Total & 31 & 100,0 \\
\hline \multicolumn{3}{|l|}{ Keluarga yang merawat } \\
\hline Istri & 26 & 83,9 \\
\hline Anak & 5 & 16,1 \\
\hline
\end{tabular}

Total $\quad 31 \quad 100,0$

Berdasarkan tabel di atas dapat dilihat bahwa karakteristik responden berdasarkan umur pada penelitian ini yaitu lebih dari setengah dari responden berusia 56-65 tahun (lansia akhir) yaitu 24 orang $(77,4 \%)$ dan kurang dari seperempat responden berusia lebih 65 tahun (manula) yaitu 7 orang $(22,6 \%)$. Karakteristik responden berdasarkan status pernikahan pada penelitian ini yaitu mayoritas berstatus menikah yaitu 26 orang $(83,9 \%)$ dan kurang dari seperempat responden berstatus duda yaitu 5 orang $(16,1 \%)$. Karakteristik responden berdasarkan pendidikan terakhir pada penelitian ini adalah seperempat dari responden yaitu tidak sekolah sebanyak 8 orang $(25,8 \%)$, kurang dari seperempat responden yaitu 6 orang $(19,4 \%)$ tamat SMA, D3, dan S1 serta 5 orang $(16,1 \%)$ tamat SMP. Karakteristik responden berdasarkan pekerjaan yaitu lebih dari seperempat responden bekerja sebagai PNS/ BUMN dan Petani sebanyak 10 orang $(32,3 \%)$, kurang dari seperempat responden bekerja sebagai wiraswata sebanyak 5 orang $(16,1 \%)$ dan 2 orang $(6,5 \%)$ responden bekerja sebagai karyawan swasta, buruh, dan tidak bekerja. Karakteristik responden berdasarkan operasi keberapa bahwa setengah dari responden telah menjalani operasi pertama yaitu 16 orang $(51,6 \%)$, lebih dari seperempat telah menjalani operasi kedua yaitu 11 orang $(35,5 \%)$ dan kurang dari seperempat responden telah menjalani operasi yaitu 4 orang (12,9\%). Karakteristik responden berdasarkan keluarga yang merawat di rumah bahwa mayoritas responden dirawat oleh istri sebanyak 26 orang $(83,9 \%)$ dan kurang dari seperempat responden dirawat oleh anaknya sebanyak 5 orang $(16,1 \%)$.

Tabel 2. Kecemasan Pasien Pre Operasi Transurethral Resection of the Prostate (TURP) di Rumah Sakit Umum Imelda Pekerja Indonesia Medan

\begin{tabular}{lcc}
\hline \multicolumn{1}{c}{ Kecemasan } & F & \% \\
\hline Tidak ada Kecemasan & 3 & 9,7 \\
\hline Kecemasan Ringan & 13 & 41,9 \\
\hline
\end{tabular}




\begin{tabular}{ccc}
\hline Kecemasan Sedang & 11 & 35,5 \\
\hline Kecemasan Berat & 4 & 12,9 \\
\hline Total & 31 & 100,0 \\
\hline
\end{tabular}

Berdasarkan tabel di atas, kecemasan Pasien Pre Operasi Transurethral Resection of the Prostate (TURP) di Rumah Sakit Umum Imelda Pekerja Indonesia Medan ditemukan bahwa kurang dari setengah responden memiliki kecemasan ringan sebanyak 13 orang $(41,9 \%)$, lebih dari seperempat responden memiliki kecemasan sedang sebanyak 11 orang $(35,5 \%)$, dan kurang dari seperempat responden memiliki kecemasan berat sebanyak 4 orang $(12,9 \%)$ serta 3 orang responden $(9,7 \%)$ tidak ada kecemasan.

Tabel 3. Kualitas Tidur Pasien Pre Operasi Transurethral Resection of the Prostate (TURP) di Rumah Sakit Umum Imelda Pekerja Indonesia Medan

\begin{tabular}{lcc}
\hline \multicolumn{1}{c}{ Kualitas Tidur } & F & \% \\
\hline Kualitas Tidur Baik & 5 & 16,1 \\
\hline Kualitas Tidur Ringan & 11 & 35,5 \\
\hline Kualitas Tidur Sedang & 15 & 48,4 \\
\hline \multicolumn{1}{c}{ Total } & 31 & 100,0 \\
\hline
\end{tabular}

Berdasarkan tabel di atas, kualitas Tidur Pasien Pre Operasi Transurethral Resection of the Prostate (TURP) di Rumah Sakit Umum Imelda Pekerja Indonesia Medan ditemukan bahwa kurang dari setengah responden kualitas tidur sedang sebanyak 15 orang $(48,4 \%)$, lebih dari seperempat responden kualitas tidur ringan sebanyak 11 orang $(35,5 \%)$, dan kurang dari seperempat responden kualitas tidur baik sebanyak 5 orang $(16, \%)$.

\section{Analisa Bivariat}

Tabel 4 Hubungan Kecemasan dengan Kualitas Tidur Pasien Pre Operasi Transurethral Resection of The Prostate (TURP) di Rumah Sakit Umum Imelda Pekerja Indonesia Medan

\begin{tabular}{lccc}
\hline \multicolumn{1}{c}{$\begin{array}{c}\text { Hubungan } \\
\text { Variabel }\end{array}$} & $\begin{array}{c}\boldsymbol{p} \text { - } \\
\text { value }\end{array}$ & $\begin{array}{c}\text { Kekuatan } \\
\text { Korelasi } \\
(\boldsymbol{r})\end{array}$ & $\begin{array}{c}\text { Arah } \\
\text { Korelasi }\end{array}$ \\
\hline $\begin{array}{l}\text { Hubungan } \\
\text { Kecemasan }\end{array}$ & 0,00 & 0,907 & $\begin{array}{c}\text { Searah } \\
(+)\end{array}$ \\
\hline
\end{tabular}

dengan Kualitas

Tidur

Berdasarkan tabel di atas, hasil penelitian ini menunjukkan ada hubungan kecemasan dengan kualitas tidur pasien pre operasi Transurethral Resection of The Prostate (TURP) di Rumah Sakit Umum Imelda Pekerja Indonesia Medan dengan nilai signifikannya 0,00 yang artinya nilai signifikan < 0,05. Kekuatan hubungan kelelahan dan aktivitas fisik bernilai 0,907 dimana nilai 0,76 sampai 0,99 menunjukkan korelasi sangat kuat. Kriteria arah korelasi penelitian ini bernilai positif yang dapat diartikan bahwa hubungan kedua variabel searah dimana semakin turun nilai kecemasan (kecemasan menuju ke ringan) maka nilai dari kualitas tidur juga menurun (kualitas tidur menuju baik).

\section{PEMBAHASAN}

\section{Kecemasan Pasien Pre Operasi Transurethral Resection of the Prostate (TURP) di Rumah Sakit Umum Imelda Pekerja Indonesia Medan}

Berdasarkan hasil penelitian kecemasan pasien pre operasi transurethral resection of the prostate (TURP) di Rumah Sakit Umum Imelda Pekerja Indonesia Medan ditemukan bahwa kurang dari setengah dari responden memiliki kecemasan ringan sebanyak 13 orang $(41,9 \%)$. Kecemasan muncul karena pasien sangat takut apabila operasi gagal, khawatir jika luka operasi tidak sembuh, dan pulihnya butuh waktu yang lama. Hasil penelitian ini kebanyakan mengalami kecemasan ringan karena pasiennya sudah ada yang pernah menjalani operasi sebelumnya, beberapa pasien semangat menjalani operasi karena adanya dukungan yang kuat dari keluarganya dan rata-rata pasien sudah pasrah akan kondisinya.

Hasil penelitian menunjukkan bahwa $50 \%$ mengalami kecemasan sedang, 33,3\% kecemasan ringan dan 16,7\% kecemasan berat pada pasien pre operasi Benign Prostat Hiperplasia (BPH) di RSUD Prof. Margono Soekarjo [7]. Tingginya angka penderita 
yang mengalami kecemasan sedang, dapat dikaitkan dengan faktor-faktor resiko yang dapat menimbulkan kecemasan. Hal ini disebabkan karena pasien merasa takut karena akan dilakukan operasi, takut jika sakitnya tidak sembuh, takut terhadap peralatan operasi, selain itu juga karena takut akan kematian.

Hasil penelitian ini sejalan dengan hasil penelitian untuk pasien pre operasi secara umumnya bahwa sebanyak $46,7 \%$ responden mengalami kecemasan ringan dan $51,1 \%$ mengalami kecemasan sedang pada pasien pre operasi di Ruangan Bougenville RSUD Sleman [8]. Pasien dari hasil penelitian ini kebanyakan khawatir akan hasil operasinya nanti, takut ketika memasuki ruangan operasi, takut nyeri yang akan muncul setelah operasi, perubahan citra tubuh, perubahan fungsi tubuh, dan kematian.

Hasil penelitian juga menunjukkan bahwa $60 \%$ pasien pre operasi di Ruangan Wijaya Kusuma RSUD Dr. R. Soeprapto Cepu mengalami kecemasan berat [9]. Hal tersebut terjadi karena tindakan invasive yang menimbulkan kecemasan karena terdapat ancaman terhadap tubuh, integritas dan jiwa pasien.

Kecemasan merupakan respon individu terhadap suatu keadaan yang tidak menyenangkan dan dialami oleh semua makhluk hidup dalam kehidupan sehari-hari. Faktor yang dapat mempengaruhi kecemasan seseorang yang menderita sakit akan lebih mudah mengalami kecemasan dibandingkan dengan orang yang tidak sakit. Kecemasan merupakan reaksi umum terhadap penyakit karena penyakit dirasakan suatu ancaman terhadap kehidupan, kesehatan dan keutuhan tubuh, rasa malu, ketidaknyamanan karena nyeri dan kelelahan [10].

Kecemasan yang dialami pasien mempunyai bermacam-macam alasan diantaranya adalah cemas menghadapi ruangan operasi dan peralatan operasi, cemas menghadapi body image yang berupa cacat anggota tubuh, cemas dan takut mati saat dibius, cemas bila operasi gagal, cemas masalah biaya yang membengkak [11].
Tindakan operasi adalah suatu stressor yang dapat menimbulkan stress fisiologi (respon neuroendokrin), stress psikologis (cemas dan takut), dan stress sosial yang membutuhkan keluarga untuk beradaptasi terhadap perubahan peran [12].

Tindakan pembedahan dan anestesi merupakan tindakan yang mendatangkan stress, karena terdapat ancaman terhadap integritas tubuh dan jiwa seseorang. Adanya stress dapat menimbulkan kecemasan terhadap pasien. Beberapa studi yang pernah dilakukan menyatakan bahwa sekitar $60 \%$ $80 \%$ pasien yang akan menjalani operasi mengalami kecemasan pre operasi dan pre anestesi dalam berbagai tingkatan. Faktorfaktor yang mengakibatkan cemas yaitu usia pasien, pengalaman, konsep diri dan peran ,tingkat pendidikan, akses informasi, tindakan operasi, tingkat sosial ekonomi, kondisi medis [13]. Hal ini sejalan dengan hasil penelitian ini bahwa lebih dari seperempat responden memiliki pendidikan SD dan hasil wawancara ditemukan bahwa mereka sangat cemas apabila tindakan operasi gagal yang dapat membahayakan kehidupan pasien. Selain itu, mayoritas responden berusia lansia akhir dan lebih dari setengah tidak memiliki pengalaman tindakan operasi yang ditunjukkan bahwa tindakan TURP adalah tindakan invasive pertama.

Kecemasan pada pasien pre operasi harus segera diatasi karena dapat menimbulkan perubahan-perubahan lanjut secara fisik yang akan menghambat dilakukannya tindakan operasi sehingga dapat memperlambat proses penyembuhan pasien. Secara fisik kecemasan dapat memicu kelenjar adrenalin untuk melepas hormonhormon efineprin yang kemudian menggerakkan hormon tubuh tersebut untuk mengatasi situasi yang mengancam. Hormonhormon tersebut akan meningkatkan detak jantung, frekuensi pernafasan dan tekanan darah [14].

Keadaan cemas yang relatif tidak tinggi dimungkinkan oleh operasi yang dilakukan merupakan operasi elektif atau operasi dengan perencanaan, dimana pasien 
sudah terlebih dahulu diinformasikan oleh tim medis khususnya dokter yang merawat tentang rencana dan prosedur yang akan dilakukan sebelum operasi.

\section{Kualitas Tidur Pasien Pre Operasi Transurethral Resection of the Prostate (TURP) di Rumah Sakit Umum Imelda Pekerja Indonesia Medan}

Kualitas Tidur Pasien Pre Operasi Transurethral Resection of the Prostate (TURP) di Rumah Sakit Umum Imelda Pekerja Indonesia Medan ditemukan bahwa kurang dari setengah responden kualitas tidur sedang sebanyak 15 orang $(48,4 \%)$, lebih dari seperempat responden kualitas tidur ringan sebanyak 11 orang $(35,5 \%)$, dan kurang dari seperempat responden kualitas tidur baik sebanyak 5 orang $(16, \%)$. Beberapa pasien berpendapat bahwa kebanyakan pasien sulit tidur karena adanya rasa nyeri pada daerah perkemihan, adanya rasa takut yang berlebih ketika akan dilakukannya operasi, berfikir apa yang akan terjadi setelah operasi, dan berfikir apayang harus dilakukan apabila operasi gagal,

Sebagian besar responden memiliki kualitas tidur tidak baik sebanyak 35 orang $(66,0 \%)$, sedangkan responden yang memiliki kualitas tidur baik sebanyak 18 orang $(34,0 \%)$ pada pasien pre operasi [15]. Menurut analisa peneliti banyaknya pasien yang mengalami kualitas tidur yang tidak baik disebabkan karena perasaan gugup dan panik perihal tentang operasi penyakit yang akan dijalani dan hal ini tidak hanya menimpa pasien tetapi juga keluarga yang menjaganya.

Hasil penelitian menunjukkan bahwa $90,5 \%$ mengalami kualitas tidur yang buruk dan 9,5\% mengalami kualitas tidur yang baik pada pasien sebelum dilakukannya tindakan operasi [6]. Kualitas tidur buruk terjadi karena adanya kecemasan yang berlebihan dimana kecemasan yang timbul karena adanya rasa takut untuk menjalani operasi.

Tidur adalah proses dimana mata tertutup selama beberapa periode yang memberikan istirahat total bagi mental dan aktivitas fisik manusia, kecuali fungsi beberapa organ vital seperti jantung, paruparu, hati, sirkulasi darah dan organ dalam lainnya. Tidur sangat penting dalam memelihara fungsi kognitif dikarenakan tidur berfungsi untuk melancarkan aliran darah ke otak, meningkatkan aktivitas korteks, meningkatkan konsumsi oksigen dan meningkatkan pengeluaran epinefrin [16]. Kehilangan tidur, bahkan untuk satu malam, dapat memicu perubahan signifikan di seluruh tubuh. Otak akan mengalami gangguan kognitif, penurunan ingatan, dan perubahan kimia otak yang dapat menyebabkan depresi [17].

Kualitas dan kuantitas tidur dapat dipengaruhi dari usia, jenis kelamin, penyakit,obat dan substansi, gaya hidup, stress emosional, lingkungan, dan makanan. Selain itu juga kesulitan tidur juga terjadi karena mayoritas responden mengalami kecemasan karena adanya rencana tindakan operasi.

Pasien pre operasi sangat membutuhkan tidur karena saat individu dalam perawatan, tubuh mengalami beberapa gangguan yang menyebabkan penurunan kualitas tidur. Penurunan kualitas tidur pasien dikarenakan suasana lingkungan rumah sakit yang terlalu ramai dan kondisi pasien sebelahnya mengerang kesakitan. Kebutuhan untuk istirahat dan tidur adalah penting bagi kualitas hidup semua orang dikarenakan pada kondisi sakit membutuhkan istirahat untuk pemulihan [18].

Tidur memiliki peranan yang sangat penting dimana pemenuhan kebutuhan tidur pada pasien pre operasi memiliki tujuan sebagai persiapan aspek fisik dan psikologi yang berpengaruh pada tingkat risiko intra operasi, mempercepat pemulihan, dan menurunkan komplikasi pasca operasi [11].

Pasien yang akan menjalani operasi TURP banyak mengalami kesulitan tidur karena rasa takut akan tindakan operasi. Kesulitan tidur dapat menganggu fungsi fisiologi tubuh seperti kurangnya oksigen sampai ke oak yang enyebabkan nyeri kepala, jantung berdenyut dengan cepat dan badan tampak lemas. Selain itu juga apabila kebutuhan tidur tidak terpenuhi dapat 
menyebabkan terganggunya pembentukan jaringan baru untuk penyembuhan luka operasi. Oleh karena itu, sangat penting dianjurkan kepada pasien untuk tetap tenang dan tidur dengan baik agar kondisi tubuh tetap kuat dalam menjalani operasi.

Hubungan Kecemasan dengan Kualitas Tidur Pasien Pre Operasi Transurethral Resection of the Prostate (TURP) di Rumah Sakit Umum Imelda Pekerja Indonesia Medan

Hasil penelitian ini menunjukkan ada hubungan kecemasan dan kualitas Tidur Pasien Pre Operasi Transurethral Resection of the Prostate (TURP) dengan nilai signifikannya 0,028 yang artinya nilai signifikan $<0,005$. Hasil wawancara pada responden menunjukkan bahwa mereka merasa takut dan cemas sampai terbawa mimpi sehingga mereka sulit untuk tidur dan sering sekali terbangun dari tidur.

Hasil ini sejalan dengan hasil penelitian sebelumnya yang dilakukan menggunakan uji Chi-Square didapatkan nilai $p=0,008<0,05$ yang berarti ada hubungan tingkat kecemasan dengan kualitas tidur pada pasien pre operasi di Rumah Sakit Umum Sundari Medan [19]. Hasil penelitian menunjukkan adanya hubungan bermakna anatara kecemasan dengan kualitas tidur pasien pre operasi di Ruangan Kenanga Rumah Sakit Pelni Jakarta dimana 14 responden $(46,7 \%)$ tidak cemas dalam menghadapi operasi sedangkan 16 responden $(53,3 \%)$ cemas menghadapi operasi, dan 17 responden $(56,7 \%)$ tidak mengalami gangguan tidur sedangkan 13 responden $(43,3 \%)$ mengalami gangguan tidur [20].

Rasa khawatir maupun cemas terhadap masalah pribadi atau situasi kerap kali mengganggu tidur. Kondisi stres emosional dapat menyebabkan seseorang menjadi tegang dan menimbulkan frustasi ketika seseorang sulit tidur. Kecemasan dapat meningkatkan kadar epinefrin melalui stimulus sistem saraf simpatis yang mana dapat mengakibatkan tahap 4 NREM dan REM memendek sehingga dapat dikatakan bahwa situasi stres menyebabkan seseorang berusaha untuk dapat tertidur namun sering terbangun selama siklus tidur atau menjadi terlalu banyak tidur. Apabila kondisi stres ini dibiarkan terlalu lama, dapat menjadi kebiasan tidur yang tidak baik.

Oleh karena itu, kecemasan yang dirasakan ketika sebelum tindakan operasi harus diatasi dengan cepat karena apabila tidak diatasi dengan cepat dapat mengakibatkan pasien sulit untuk tidur dan dapat menurunkan kondisi fisik pasien. Menurunnya kondisi fisik pasien dapat memperlambat proses penyembuhan ketika selesai operasi.

\section{KESIMPULAN}

Berdasarkan penelitian yang dilakukan terdapat hubungan kecemasan dengan kualitas Tidur Pasien Pre Operasi Transurethral Resection of the Prostate (TURP) di Rumah Sakit Umum Imelda Pekerja Indonesia Medan

\section{SARAN}

Diharapkan perlu adanya tindakan keperawatan yang dapat mengurangi kecemasan agar kualitas tidur pasien dapat menjadi lebih baik.

\section{REFERENSI}

1. Reverehealth. (2018). BPH prevention and treatment. Diakses dari: https://reverehealth.com/live-better/bphprevention-and-treatment/

2. Zuhirman, Z., Juananda, D., \& Lestari, P. (2017). Gambaran komplikasi transurethral resection of the prostate pada pasien benign prostatic hyperplasia. Jurnal Ilmu Kedokteran, 10(1), 44-53.

3. Novelty, R., Rofinda, Z. D., \& Myh, E. (2019). Korelasi lama operasi dengan perubahan kadar natrium pasca operasi transurethral resection of the prostate di RSUP Dr. M. Djamil Padang. Jurnal Kesehatan Andalas, 8(1), 37-42.

4. Jaya, K. (2015). Keperawatan jiwa. Tanggerang selatan : Binarupa Aksara

5. Kurniawan, A., Armiyati, Y., \& Astuti, R. (2013). Pengaruh pendidikan kesehatan pre operasi terhadap tingkat 
kecemasan pada pasien pre operasi hernia di RSUD Kudus. FIKkeS, 6(2).

6. Nafiah, S. I. (2019). Gambaran tingkat kualitas tidur pada pasien pre operative di Rumah Sakit Tingkat III Baladhika Husada Jember. Doctoral dissertation, Fakultas Keperawatan.

7. Susanti., Khasanah, S., \& Muliana (2016). Hubungan tingkat kecemasan dengan peningkatan tekanan darah pada pasien pre operasi benigna prostat hiperplasia (BPH) di RSUD Prof. Dr. Margono Soekarjo. Viva Medika, Volume 09/ Nomor 16/ Februari/ 2016

8. Arifah, S., \& Trise, I. N. (2012). Pengaruh pemberian informasi tentang persiapan operasi dengan pendekatan komunikasi terapeutik terhadap tingkat kecemasan pasien pre operasi di Ruang Bougenville RSUD Sleman. Jurnal Kebidanan, 4(1).

9. Lestari, K. P., \& Yuswiyanti, A. (2018). Pengaruh relaksasi otot progresif terhadap penurunan tingkat kecemasan pada pasien pre operasi di Ruang Wijaya Kusuma RSUD DR. R Soeprapto Cepu. Jurnal Keperawatan Maternitas, 3(1), 27-32.

10. Carpenito, L, J. (2017). Diagnosa Keperawatan Aplikasi Pada Praktek Klinis. Jakarta : EGC

11. Smeltzer, S, C., \& Bare, B, G. (2013). Buku Ajar Keperawatan Medikal Bedah Edisi 8. Jakarta : EGC.

12. Baradero, M., Dayrit M. W., \& Siswadi Y. (2019). Prinsip Dan Praktik Keperawatan Perioperatif. Jakarta: EGC.

13. Taravella, D., Ratna, W., \& Susana, S. A. (2017). Hubungan pengetahuan operasi dengan tingkat kecemasan pre operasi pasien dengan tindakan spinal anestesi. Doctoral dissertation, Politeknik Kesehatan Kementerian Kesehatan Yogyakarta.

14. Vist, W, N., Priyanto, P., \& Wakhid, A. (2018). Perbedaan tingkat kecemasan pada pasien preoperasi bph sebelum dan sesudah pemberian terapi musik alam di Rsud Ambarawa. Doctoral dissertation, Universitas Ngudi Waluyo.
15. Setyawan, A, B. (2017). Hubungan tingkat kecemasan dengan kualitas tidur pasien pre operasi di Ruang Angsoka Rumah Sakit Abdul Wahab Sjahranie Samarinda. Jurnal Ilmiah Sehat Bebaya, 1(2).

16. Arifin Z. (2011). Analisis hubungan kualitas tidur dengan kadar glukosa darah pasien diabetes melitus tipe 2 di rumah sakit umum Propinsi Nusa Tenggara Barat. Tesis. Jakarta: Universitas Indonesia.

17. Reza, R, R., Berawi, K., Karima, N., \& Budiarto, A. (2019). Fungsi tidur dalam manajemen kesehatan. Jurnal Majority, 8(2), 247-253.

18. Potter, A \& Perry, A 2012, Buku ajar fundamental keperawatan; konsep, proses, dan praktik, vol.2, edisi keempat. Jakarta : EGC.

19. Muflih. (2019). Hubungan tingkat kecemasan dengan kualitas tidur pasien pre operasi di Rumah Sakit Umum Sundari Medan. Retrieved from http://download.garuda.ristekdikti.go.id/

20. Andika, B. (2014). Hubungan tingkat kecemasan klien preoperasi dengan gangguan pola tidur di ruang kenanga Rumah Sakit Pelni Jakarta. Retrieved from http://www.akbiambarawai.ac.id/ file/jurnaledisil.pdf 